\title{
PENGEMBANGAN BAHAN AJAR BERBASIS APLIKASI GEOGEBRA PADA MATERI BANGUN RUANG SISI DATAR BERDASARKAN KEMAMPUAN PEMAHAMAN MATEMATIS SISWA
}

\author{
Maulana', Lala Nailah Zamnah², Asep Amam³ \\ 1,2,3Program Studi Pendidikan Matematika, Universitas Galuh, J.L. R. E. Martadinata No.150, Ciamis, Indonesia \\ Email: maulanamalikibrahim170797@gmail.com
}

\begin{abstract}
This study aims to develop Geogebra application-based teaching materials on Plane Geometry materials based on the students' ability of mathematical understanding in SMP Negeri 1 Lumbung in the school year of 2020/2021; and is in accordance with the quality criteria set. This development research uses the ADDIE model (Analysis, Design, Development, Implementation, and Evaluation) which is limited to the development stage only. The analysis stage is done by analyzing the curriculum, media and material needs. The Design stage is carried out by collecting data and designing teaching materials. While in the development stage, the product framework and validating and revising teaching materials based on validator input is applied. The object of this research is Geogebra-based teaching materials based on mathematical understanding abilities. The instrument is a validation sheet which is in the form of a checklist regarding the quality of teaching materials that have criteria ranging from 1-5 with a very poor-very good category. The results of data analysis shows that the feasibility assessment of teaching materials based on the quality aspect of the content is $92.14 \%$; the implementation is $86.43 \%$; the language is $84.29 \%$; the software display is $91.84 \%$; and the usage aspect is $88.57 \%$. The average feasibility assessment is $89.57 \%$ which is included in the very good category; and it means that the Geogebra-based teaching materials developed has met the quality standards set and are suitable to be used. The result of $Q$-Cochran test reveals that the calculated $Q$ value obtained is $17.618<Q$ Table $(X 2)(\alpha=0.05$; $k$ $1=19)=38,58226$; and based on the significance value obtained, $0.548>=0.05, \mathrm{HO}$ is Accepted. The result come up with the validator's assessment of the teaching materials developed are "the same, or, there is no difference". It means that the teaching materials are in the category of high validity and it indicates very good.
\end{abstract}

Keywords: Teaching Materials, Plane Geometry, Geogebra, Comprehension Ability, Development.

\begin{abstract}
ABSTRAK
Penelitian ini bertujuan untuk mengembangkan bahan ajar berbasis aplikasi Geogebra pada materi bangun ruang sisi datar berdasarkan kemampuan pemahaman matematis siswa SMP Negeri 1 Lumbung tahun pelajaran 2020/2021 yang sesuai dengan kriteria kualitas yang ditetapkan. Penelitian ini merupakan penelitian pengembangan model ADDIE (Analysis, Design, Development, Implementation, dan Evaluation) yang dibatasi sampai pada tahap development. Tahap analysis dilakukan dengan menganalisis kebutuhan kurikulum, media dan materi. Tahap Design dilakukan dengan mengumpulkan data dan membuat rancangan bahan ajar sedangkan pada tahap development yaitu menerapkan kerangka produk dan memvalidasi serta merevisi bahan ajar berdasarkan masukan validator. Objek penelitian ini adalah bahan ajar berbasis Geogebra berdasarkan kemampuan pemahaman matematis. Instrumen yang digunakan adalah yaitu lembar validasi berbentuk checklist mengenai kualitas bahan ajar yang memiliki kriteria pada rentang 1-5 dengan kategori sangat kurang-sangat baik. Berdasarkan hasil analisis data menunjukan bahwa penilaian kelayakan bahan ajar berdasarkan aspek kualitas isi 92,14\%, keterlaksanaan $86,43 \%$, kebahasaan $84,29 \%$, tampilan software $91,84 \%$ dan aspek penggunaan $88,57 \%$. Rata-rata penilaian kelayakan yaitu $89,57 \%$ dan termasuk dalam kategori sangat baik artinya bahan ajar berbasis Geogebra yang dikembangkan telah memenuhi standar kualitas yang ditetapkan dan layak digunakan. Hasil Uji Q-Cochran didapat Nilai Q hitung yang didapat yaitu 17,618 < Q Tabel (X2)( $\alpha=0,05$;k$1=19)=38,58226$. Berdasarkan Nilai Signifikansi yang didapat yaitu $0,548>a=0,05$, maka HO diterima. Kesimpulanya, hasil penilaian validator terhadap bahan ajar yang dikembangkan adalah "sama/tidak terdapat perbedaan" yaitu bahan ajar masuk kategori validitas tinggi yaitu sangat baik.
\end{abstract}

Kata Kunci: Bahan Ajar, Bangun Ruang Sisi Datar,Geogebra, Kemampuan Pemahaman, Pengembangan.

Cara sitasi: Maulana., Zamnah, L.N., \& Amam, A. (2021). Pengembangan bahan ajar berbasis aplikasi geogebra Pada materi bangun ruang sisi datar berdasarkan kemampuan pemahaman matematis siswa. J-KIP (Jurnal Keguruan dan IImu Pendidikan), 2 (2), 1-8. 


\section{PENDAHULUAN}

Matematika adalah ilmu yang mempunyai peranan yang mendasar dalam perkembangan ilmu-ilmu lainnya yang berpengaruh langsung terhadap perkembangan teknologi. Harsa (2016) yang menyatakan bahwa pembelajaran matematika harus diitegrasikan dengan teknologi informasi untuk menambah antusias belajar siswa. Pendapat ini juga didukung oleh Sulistyawati \& Wardono (2018) yang menyatakan bahwa penggunaan teknologi dalam literasi matematika sangat penting untuk mengemas pelajaran yang akan disampaikan, seringkali siswa kurang bersemangat untuk belajar karena gaya mengajar guru yang masih konvensional yaitu dengan metode ceramah, penyebab minimnya kemampuan pemahaman matematis diantaranya adalah kurangnya minat belajar siswa dikarenakan dalam penyajian materi pelajaran masih bersifat konvensional. Di samping itu yang menjadi faktor kurangnya minat belajar siswa adalah peran guru dalam memodifikasi pembelajaran serta minimnya kreatifitas guru untuk menciptakan dan menggunakan media pembelajaran matematika. Media yang di terapkan dalam proses pembelajaran matematika belum digunakan secara maksimal. Salah satu contohnya ketika membahas bangun tiga dimensi yang pada dasarnya siswa kesulitan untuk membayangkan dari bentuk gambar ke bentuk yang sebenarnya dan sebaliknya. Kemampuan membayangkan siswa umumnya sangat terbatas sedangkan guru menghendaki agar siswa dapat menyerap pelajaran yang disampaikan dengan maksimal. Dengan keadaan yang seperti ini perlu diadakan pembaharuan dengan menggunakan media yang sesuai, dan tepat untuk menunjang proses pembelajaran. Maka dalam proses pembelajaran guru harus menggunakan metode-metode atau media-media pembelajaran yang menjembatani pemikiran siswa.

Penelitian mengenai pengembangan media pembelajaran telah banyak dilakukan diantaranya: (1) Penelitian Sari (2018) dengan hasil penelitian yang diperoleh yaitu penggunaan media pembelajaran aplikasi adobeflash masuk kedalam kategori menarik bagi siswa sehingga layak digunakan sebagai media pembelajaran di kelas VIII SMP pada materi bangun ruang sisi datar. (2) Penelitian Aryanto \& Setiawan (2019) dengan hasil yang diperoleh yaitu pembelajaran dengan berbasis aplikasi geogebra jelas mengalami peningkatan hasil belajar matematika sekolah SMP di Kabupaten Bogor. (3) Penelitian Octamela, et al. (2019) dengan hasil penelitian yang diperoleh menunjukan bahwa pemahaman konsep matematis siswa meningkat dengan menggunakan buku elektronik interaktif berbantuan geogebra.

GeoGebra merupakan aplikasi pembelajaran matematika dinamis yang dikembangkan oleh Markus Hohenwarter untuk pembelajaran di sekolah-sekolah dan bersifat open source. Menurut Hohenwarter dalam (Octamela, Suweken \& Ardana, 2019), Geogebra adalah program komputer untuk membelajarkan matematika khususnya geometri dan aljabar. Software geogebra dapat dimanfaatkan sebagai media pembelajaran matematika untuk mendemonstrasikan atau memvisualisasikan konsep-konsep matematis. Hal ini sejalan dengan (Agung, Ma'Ruffi \& Muhammad, 2019) kemampuan visualisasi dinamis yang dimiliki geogebra dapat meningkatkan konsep-konsep matematika dalam meningkatkan pemahaman matematis siswa. Melalui geogebra, guru dapat mengeksplorasi materi geometri dan meningkatkan penalaran matematis serta memvisualisasikan konsep matematis. Selain itu, geogebra merupakan alat yang sangat efektif untuk pembelajaran matematika di sekolah (Octamela, Suweken \& Ardana 2019).

Salah satu topik dalam aspek geometri di kelas delapan semester dua yaitu membahas tentang bangun ruang sisi datar. Penggunaan aplikasi geogebra dapat mempermudah dalam memahami konsep-konsep bangun ruang sisi datar karena aplikasi geogebra dapat membantu menampikan bangun ruang sisi datar tampak seperti nyata 3 dimensi, dengan fasilitas-fasilitas yang disediakan dalam aplikasi geogebra materi bangun ruang sisi datar dapat dikemas semenarik mungkin bisa dengan merubah warna agar terlihat lebih menarik serta pengaturan kekontrasan warna yang dapat menampilkan bangun ruang tampak seperti nyata sehingga menambah antusias belajar siswa yang diharapkan dapat menambah motivasi belajar siswa sehingga terjadi peningkatan 
kemampuan pemahaman matematis siswa. Oleh karena itu, tujuan penelitian ini yaitu untuk mengembangan bahan ajar berbasis aplikasi Geogebra pada materi bangun ruang sisi datar berdasarkan kemampuan pemahaman matematis siswa SMP Negeri 1 Lumbung tahun pelajaran 2020/2021 yang sesuai dengan kriteria kualitas yang ditetapkan.

\section{METODE PENELITIAN}

Metode penelitian yang digunakan dalam penelitian ini adalah penelitian pengembangan yang bertujuan menghasilkan produk tertentu dan menguji kualitas produk tersebut. Produk yang dihasilkan dalam penelitian ini adalah bahan ajar berbasis aplikasi Geogebra pada materi bangun ruang sisi datar berdasarkan kemampuan pemahaman matematis siswa. Model penelitian yang digunakan yaitu Model ADDIE (Analysis, Design, Development, Implementation and Evaluation) yang dikembangkan oleh Furthermore, Lee dan Owens. Namun dalam penelitian ini pelaksanaan pengembangan dibatasi pada tahap Analysis, Design dan Developement pada langkah validasi.

1. Tahap pertama yang dilakukan yaitu analysis. Tujuan dari tahap ini menurut Branch (2009) yaitu untuk mengidentifikasi kemungkinan penyebab kesenjangan yang terjadi. Oleh karena itu, pada tahap ini dilakukan penelitian pendahuluan yaitu wawancara terhadap guru mata pelajaran matematika untuk memperoleh data aspek analisa kebutuhan yaitu analisis kurikulum, media dan materi.

2. Tahap design menurut Branch (2009) bertujuan untuk meverifikasi kinerja yang diinginkan dan metode pengujian yang tepat. dilakukan untuk merancang bahan ajar berbasis aplikasi geogebra sesuai unsur-unsur yang dibutuhkan dimana tahapannya meliputi pengumpulan data dan membuat rancangan bahan ajar.

3. Tahap development dilakukan untuk menerapkan kerangka dan memvalidasi bahan ajar oleh validator dimana tahapannya meliputi pengembangan rancangan menggunakan Geogebra dan validasi desain untuk mengetahui kelayakan bahan ajar.

Instrumen yang digunakan dalam penelitian ini yaitu lembar validasi berbentuk checklist. Lembar validasi digunakan untuk memperoleh penilaian pada tahapan development yang dilihat berdasarkan aspek kualitas isi, kebahasaan, keterlaksanaan, tampilan software, dan penggunaan dimana pada tiap butir penilaian memiliki kriteria pada rentang 1-5 dengan kategori sangat kurang-sangat baik. Pada butir yang dinilai kurang, para ahli akan memberikan saran perbaikan, kemudian data yang dihasilkan dari lembar penilaian tersebut akan dirubah ke dalam skala satu sampai dengan lima untuk memudahkan analisis data lalu di interpretasikan hasilnya berdasarkan skala likert. Data yang telah terkumpul dihitung skor rata-rata setiap kriteria yang dinilai. Setelah itu untuk melihat kelayakan bahan ajar dari hasil data penilaian validasi ahli menggunakan rating scale karena menurut Sugiyono dengan rating scale, data mentah yang diperoleh berupa angka kemudian dapat ditafsirkan dalam pengertian kualitatif. Selanjutnya data penelitian yang bersifat kualitatif seperti komentar dan saran akan dijadikan dasar dalam merevisi bahan ajar berbasis multimedia ini. Langkah terakhir adalah menyimpulkan hasil perhitungan berdasarkan tabel di bawah ini. Jika interpretasi hasil validasi ahli baik atau sangat baik maka dapat disimpulkan hasil pengembangan bahan ajar berbasis aplikasi geogebra berdasarkan kemampuan pemahaman matematis siswa adalah valid.

\section{HASIL DAN PEMBAHASAN}

Penelitian ini bertujuan untuk menghasilkan dan mengembangkan media pembelajaran matematika interaktif berbasis aplikasi Geogebra pada materi Bangun Ruang Sisi Datar kelas VIII SMP. Hasil dari pelaksanaan pengembangan diuraikan sebagai berikut. 
1) Tahap Analysis

Tahapan pertama yaitu analisis yang dilakukan untuk mengetahui apa tujuan dikembangkan dan untuk siapa ditujukan media pembelajaran multimedia. Pada tahap ini dilakukan penelitian pendahuluan yaitu wawancara terhadap guru mata pelajaran matematika untuk memperoleh data aspek analisa kebutuhan. Adapun data yang diperoleh antara lain :

a. Analisis Kurikulum

Kurikulum yang diterapkan pada mata pelajaran matematika kelas VIII SMP adalah kurikulum 2013. Langkah awal dalam analisis kurikulum yaitu memilih materi matematika. Adapun kompetensi dasar yang digunakan dalam penelitian ini adalah membedakan dan menentukan luas permukaan dan volume bangun ruang sisi datar (kubus,balok, prisma, dan limas) dan menyelesaikan masalah yang berkaitan dengan luas permukaan dan volume bangun ruang sisi datar (kubus, balok, prima dan limas), serta gabungannya.

b. Analisis Media

Analisis media pembelajaran bertujuan untuk mengetahui media pembelajaran seperti apa yang diterapkan sebelumnya di mata pelajaran matematika khususnya pada materi bangun ruang sisi datar. Adapun data yang diperoleh dalam analisis media pembelajaran yang digunakan yaitu:

- Pada saat pembelajaran matematika khususnya materi bangun ruang sisi datar, guru menggunakan metode konvensional dan bahan ajar yang digunakan yaitu buku paket siswa, LKS serta modul yang dibuat oleh guru tetapi untuk penggunaan software itu belum pernah dilakukan. Selain itu, guru juga menggunakan alat peraga bangun ruang yang terbuat dari plastik.

- Media yang digunakan tersebut tidak bersifat interaktif yang berarti tidak memerlukan interaksi dari siswa terhadap media pembelajaran sehingga menjadikan siswa cenderung pasif dalam mengikuti pembelajaran matematika. Siswa cenderung belum mengerti mengenai unsur-unsur dari bangun ruang sisi datar seperti membedakan antara diagonal bidang dengan bidang diagonal, menghitung luas permukaan dan volume limas, seringkali tinggi limas dijadikan tinggi bidang segitiga padahal untuk mencari tinggi bidang segitiga harus menggunakan rumus phytagoras.

Berdasarkan data yang diperoleh bahwa media pembelajaran yang digunakan oleh guru matematika di SMPN 1 Lumbung masih kurang optimal terutama saat memberikan gambaran visual bangun ruang sisi datar yang seharusnya berbentuk tiga dimensi menjadi gambar 2 dimensi sehingga siswa cenderung mengalami kesulitan dan itu berpengaruh terhadap minat siswa untuk belajar matematika. Oleh karena itu peneliti ingin mengembangkan media pembelajaran yang bersifat interaktif menggunakan aplikasi geogebra. Pemilihan aplikasi Geogebra ini dikarenakan kemampuannya dalam menampilkan multimedia, animasi, gabungan grafis dan interaksi dengan pengguna. Analisis teknologi yang dilakukan yaitu dengan cara berdiskusi dengan dosen pembimbing, ahli media dan guru mata pelajaran untuk mengetahui kecocokan aplikasi Geogebra dengan materi yang ditentukan.

c. Analisis Materi

Analisis materi yaitu dengan mengidentifikasi kompetensi inti dan kompetensi dasar mata pelajaran matematika. Dari identifikasi tersebut maka didapatkan materi yang akan dimasukkan dalam media pembelajaran dan disusun secara sistematis untuk disajikan pada media pembelajaran interaktif antara lain materi balok, kubus, prisma dan limas yang masing-masing terdiri dari sub bab materi yaitu definisi, unsur-unsur, jaring-jaring, luas permukaan dan volume. 
2) Tahap Design

Tahap design bertujuan untuk merancang bahan ajar berbasis aplikasi geogebra sesuai unsurunsur yang dibutuhkan dengan diagram alur yang terdiri dari (1) Cover; (2) Petunjuk Penggunaan; (3) Peta Konsep; (4) Kompetensi Dasar; (5) Materi; (6) Latihan Soal; (7) Profil. Pada bagian materi terbagi menjadi empat bagian yaitu materi balok, kubus, prisma dan limas dengan masing-masing terdiri dari sub bab materi yaitu definisi, unsur-unsur, jaring-jaring, luas permukaan dan volume.

3) Tahap Development

Tahap development dilakukan dengan cara menerapkan kerangka produk dan tahap validasi ahli. Setelah bahan ajar bangun ruang sisi datar berbasis Geogebra dikembangkan sesuai dengan design yang telah dibuat, selanjutnya dilakukan validasi untuk mengetahui kelayakan media pembelajaran interaktif yang dikembangkan dan nantinya mendapatkan saran perbaikan. Terdapat dua macam data yang diperoleh dari hasil validasi yaitu data kuantitatif dan data kualitatif. Data kuantitatif berupa hasil dari angket penilaian dengan skala likert. Sedangkan data kualitatif berupa penilaian tambahan atau saran dari ke tujuh validator.

Berikut ini rekapan komentar/saran perbaikan bahan ajar bangun ruang sisi datar berbasis geogebra dari ke tujuh validator.

Tabel 1. Komentar/Saran Perbaikan dari Ahli

\begin{tabular}{cl}
\hline Validator & \multicolumn{1}{c}{ Komentar/Saran Perbaikan } \\
\hline Validator 1 & Pada bagian materi prisma bisa dibatasi untuk prisma segitiga siku-siku \\
Validator 2 & Tambahkan soal uji kompetensi/kuis pada bahan ajar \\
Validator 3 & Pada materi balok, gambar yang disajikan yaitu kubus \\
Validator 4 & Penamaan titik sudut disesuaikan kembali dengan keterangan yang ada pada bahan ajar \\
Validator 5 & Perbaiki pada bagian petunjuk penggunaan aplikasi agar lebih mudah dipahami \\
Validator 6 & Kunci tampilan aplikasi bahan ajar agar objek-objek tidak berubah posisi dan tidak bergeser \\
Validator 7 & $\begin{array}{l}\text { Pada bagian petunjuk penggunaan terdapat menu "evaluasi" tetapi pada bahan ajar menu } \\
\text { "latihan soal". }\end{array}$ \\
\hline
\end{tabular}

Adapun rekapan rata-rata perolehan skor yang telah dikonversi sebagai berikut.

Tabel 2. Rekap Hasil Penilaian Media Pembelajaran oleh Ahli

\begin{tabular}{lccc}
\hline \multicolumn{1}{c}{ Aspek } & Skor Hasil & Skor Kriterium & Persentase (\%) \\
\hline Kualitas Isi & 129 & 140 & $92,14 \%$ \\
Keterlaksanaan & 121 & 140 & $86,43 \%$ \\
Kebahasaan & 59 & 70 & $84,29 \%$ \\
Tampilan Aplikasi & 225 & 245 & $91,84 \%$ \\
Penggunaan & 93 & 105 & $88,57 \%$ \\
Penilaian Keseluruhan & 627 & 700 & $89,57 \%$ \\
\hline
\end{tabular}

Berdasarkan data diatas, diperoleh hasil bahwa bahan ajar bangun ruang sisi datar berbasis Geogebra menurut penilaian ahli termasuk ke dalam kriteria sangat baik dengan persentase skor sebesar 89,57 \% sehingga media pembelajaran berbasis Geogebra tidak perlu direvisi. Sedangkan berdasarkan data kualitatif yang diperoleh dari saran/komentar ahli diperlukan beberapa perbaikan.

Hasil dari Uji Q-Cochran mengguankan SPSS 1.6 untuk mengetahui ada atu tidaknya perbeadaan penilaian oleh validator hasilnya sebagai berikut : 


\section{Test Statistics}

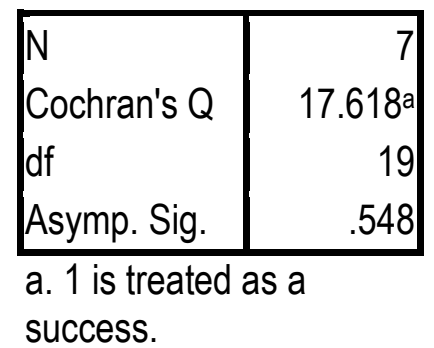

Dimana $\mathrm{N}$ adalah jumlah validator sebanyak 7 orang, Cochran' $\mathrm{Q}=17,618, \mathrm{df}=\mathrm{k}-1=20-1=19$ dan didapat nilai Signifikansi sebesar 0,548 . Nilai $Q$ dan Nilai Signifikansi sudah di dapatkan langkah berikutnya yaitu menginterpretasi dan menyimpulkan yaitu kriteria nya sebagai berikut Interpretasi hasil uji Q-Cochran adalah sebagai berikiut :

Jika Nilai $Q$ Hitung $\geq Q$ Tabel $\left(X^{2}\right)_{(\alpha=0,05 ; k-1=19)}$ Dan Nilai Signifikansi $\leq a$ Maka $\mathrm{H}_{0}$ Ditolak Jika Nilai $Q$ Hitung $<Q$ Tabel $\left(X^{2}\right)_{(\mathrm{a}=0,05 ; \mathrm{k}-1=19)}$ Dan Nilai Signifikansi $>$ a Maka $\mathrm{H}_{0}$ Diterima

Berdasarkan Nilai $Q$ hitung yang didapat yaitu 17,618 $<Q$ Tabel $\left(X^{2}\right)_{(\mathrm{a}=0,05 ; \mathrm{k}-1=19)}=38,58226$ dan berdasarkan Nilai Signifikansi yang didapat yaitu 0,548 $>a=0,05$ Maka $\mathrm{H}_{0}$ Diterima Kesimpulanya Hasil penilaian validator terhadap bahan ajar yang dikembangkan adalah "sama/tidak terdapat perbedaan" yaitu bahan ajar masuk kategori validitas tinggi yaitu sangat baik dan layak digunakan dalam pembelajaran bangun ruang sisi datar, atau semua validator menilai baik bahan ajar tersebut.

Hasil penelitian ini sejalan dengan hasil penelitian dari Agustiany, Hardi \& IImiati (2021) yakni berdasarkan data hasil analisis dan pembahasan pada penelitian ini, maka disimpulkan bahwa terdapat perbedaan hasil belajar kognitif siswa dengan menggunakan media audio visual dan media peta konsep. Hal ini diketahui dari hasil belajar dengan menggunakan media audio visual memberikan pengaruh lebih baik dibandingkan dengan hasil belajar menggunakan media peta konsep pada materi ekosistem.

\section{KESIMPULAN}

Berdasarkan analisis data hasil penelitian diperoleh hasil pencapaian pada aspek kualitas isi $92,14 \%$, keterlaksanaan $86,43 \%$, kebahasaan $84,29 \%$, tampilan software $91,84 \%$ dan aspek penggunaan $88,57 \%$. Rata-rata penilaian kelayakan yaitu $89,57 \%$ dan termasuk dalam kategori sangat baik artinya bahan ajar berbasis Geogebra yang dikembangkan telah memenuhi standar kualitas yang ditetapkan dan layak digunakan.Hasil Uji Q-Cochran didapat Nilai $Q$ hitung yang didapat yaitu $17,618<Q$ Tabel $\left(X^{2}\right)_{(\mathrm{a}=0,05 ; \mathrm{k}-1=19)}=38,58226$ dan berdasarkan Nilai Signifikansi yang didapat yaitu $0,548>\mathrm{a}=0,05 \mathrm{Maka}_{\mathrm{H}}$ Diterima Kesimpulanya Hasil penilaian validator terhadap bahan ajar yang dikembangkan adalah "sama/tidak terdapat perbedaan" yaitu bahan ajar masuk kategori validitas tinggi yaitu sangat baik.

\section{REKOMENDASI}

Sebaiknya guru atau peneliti lebih kreatif dalam memilih dan menentukan model pembelajaran yang disesuaikan dengan tujuan yang ingin dicapai, bahan materi pelajaran, juga kondisi dari peserta didik.

\section{UCAPAN TERIMA KASIH}

Penulis mengucapkan terima kasih kepada pembimbing dan validator yang telah membantu proses penelitian sehingga berjalan dengan lancar. 


\section{DAFTAR PUSTAKA}

Agung, S., Ma'Ruffi \& Muhammad, I. 2019. "Pengembangan Perangkat Pembelajaran Berbasis Media Aplikasi Geogebra Pada Materi Geometri BerdasarkanHigher Order Thinking Skills Siswa." Jurnal Matematika Dan Pembelajaran 7 (2): 194-210.

Agustiany, R., Hardi, E., \& IImiati, N. (2021). Perbedaan Hasil Belajar Kognitif Siswa melalui Penggunaan Media Audio Visual dan Media Peta Konsep pada Materi Ekosistem. J-KIP (Jurnal Keguruan dan Ilmu Pendidikan), 2 (1), 15-20.

Aryanto, Y \& Setiawan, W. 2019. "Implementasi Geogebra Pada Materi Bangun Ruang Sisi Lengkung BerdasarkanHasil Belajar Matematik Siswa SMP." Jurnal On Education 01 (03): 525-30.

Harsa, F. S. 2016. "Integrasi Ict Dalam Pembelajaran Matematika." Journal Paedagogi 8 (January): 158-62.

Octamela, K. S., Suweken, G \& I, M. A. 2019. "Pemahaman Matematis Siswa Dengan Menggunakan Buku Elektronik Interaktif Berbantuan Geogebra." JNPM (Jurnal Nasional Pendidikan Matematika) 3 (2): 305. https://doi.org/10.33603/jnpm.v3i2.1761.

Sari, R. S. P. 2018. Pengembangan Bahan Ajar Matematika Pada Materi Bangun Ruang Sisi Datar Menggunakan Software Microsoft Adobe Flash Untuk Kelas VIII SMP. Lampung: Universitas Islam Negeri Raden Intan.

Sulistyawati, A \& Wardono, K. 2018. "Pemanfaatan ICT Dalam Literasi Matematika." Prosiding Seminar Nasional Matematika (PRISMA 1) 1:1-10. 
